\title{
Study on the Radial Displacement Law and Permeability Enhancement Effect of Coal Body around Hydraulic Flushing Drilling
}

\author{
He Yang, ${ }^{1,2}$ Dejun Miao $\mathbb{D}^{1,2}$ Zhen Liu $\mathbb{D}^{1,2}$ Dawei Zhao, ${ }^{1,2}$ and Mingrui Zhang $\mathbb{D}^{1,2}$ \\ ${ }^{1}$ College of Safety and Environmental Engineering, Shandong University of Science and Technology, 579 Qianwangang Rd, \\ Huangdao District, Qingdao 266590, China \\ ${ }^{2}$ State Key Laboratory of Mining Disaster Prevention and Control Co-Founded by Shandong Province and the Ministry of Science \\ and Technology, Shandong University of Science and Technology, Qingdao 266590, China
}

Correspondence should be addressed to Dejun Miao; miaodj@sdust.edu.cn

Received 21 February 2021; Revised 15 April 2021; Accepted 18 May 2021; Published 7 June 2021

Academic Editor: Keni Zhang

Copyright $\odot 2021$ He Yang et al. This is an open access article distributed under the Creative Commons Attribution License, which permits unrestricted use, distribution, and reproduction in any medium, provided the original work is properly cited.

Hydraulic flushing drilling technology can not only improve the efficiency of high-pressure and low-permeability geological reservoir coalbed methane drainage but also effectively reduce the probability of coal and gas outburst disasters through pressure relief. The main mechanism of this technology is to expand the borehole diameter through hydraulic flushing measures, increase the strain of the coal around the borehole, and increase the development of cracked pores, to improve the permeability of the coal seam and realize the dual reduction of ground and gas pressure. However, in the actual application process, the interaction mechanism among the stress field, the structure field, and the seepage field is still not clear, and there is no clear method to accurately determine the pressure relief range based on the pressure relief mechanism in order to carry out reasonable drilling arrangements. Therefore, this article comprehensively uses laboratory experiments, numerical simulations, and field practices to fully explain the hydraulic flushing pressure relief mechanism and proposes a method to accurately determine the pressure relief range based on the radial line strain law. The results based on radial line strain showed that the effective relief radius expands to $0.86 \mathrm{~m}$ once adopting the $\Phi 579 \mathrm{~mm}$ hydraulic flushing borehole compared to $\Phi 160 \mathrm{~mm}$; the borehole's equivalent diameter of drilling field \#11 is 2 to 3 times than that of \#10 and 1.2 times the average CBM extraction amount. Therefore, as the borehole diameter increases, the permeability and radial line strain of the coal around the borehole increase significantly, but the tendency of the increase in permeability decreases with increasing vertical stress. The findings of this study can help for a better understanding of the pressure relief and permeability enhancement mechanism of hydraulic flushing, and the method of determining the pressure relief range based on radial strain can also provide a new way for other mines to practice ideas.

\section{Introduction}

In recent years, with the increasing depth of coal seam mining in China, the physical and chemical properties and the mechanical environment of the coal seam have undergone major changes [1-3]. For example, according to news reports, the 3.25 coal and gas outburst accident at Shigang Coal Mine in Shanxi Province directly caused the deaths of 4 miners; the 4.9 coal and gas outburst accident at Dongfeng Coal Mine in Guizhou Province directly caused the deaths of
8 miners in 2021. Studies have shown that there is an obvious negative correlation between ground stress and coal seam permeability. Therefore, the above situation not only exacerbates the hazards of gas-inducted and dust-inducted disasters [4-6] but also results in the difficulty of coalbed methane extraction. Increased difficulty of extraction is mainly due to the high stress and low permeability of domestic coal bed methane (CBM) reservoirs [7], which seriously restricts China's development of the CBM extraction industry. Therefore, many scholars around the world have proposed a 
number of approaches to improve the CBM extraction rate for reservoirs with such high pressure and low permeability. For example, in terms of promoting the development of the coal fracture structure, [8] proposed a 3D drainage technique based on the development of fissures during the mining process and the flow of depressured gas to improve the permeability of soft coal seams, thereby improving the efficiency of CBM extraction. As for high-pressure and lowpermeability CBM reservoirs, [9] combined theoretical research and field tests to exploit the high-pressure air blasting for cracking and permeability enhancement. It turns out that CBM reservoirs' permeability increases significantly and the CBM emission amount ascends along with CBM extraction yield. [10] conducted coal fracturing tests and proposed a technique for stimulation of natural coal fractures and cleats via the graded proppant injection targeting a uniform cleat filling by the proppant to keep the natural pore and fracture structure intact. In addition, fracturing promotes the development of new cracks to increase coal porosity, thereby enhancing coal permeability and CBM extraction rate. [11] proposed a technique for coal fracturing by means of static crushing to improve the permeability and the gas drainage capacity of high gas pressure and low-permeability soft coal seam. [12] used the capacitance with high capacity to generate abruptly electrical impact wave to split a coal seam, which is called the high-voltage electrical pulse technique. In terms of changing the temperature of CBM reservoirs, [13] experimentally examined the evolution of permeability for natural low-rank coal samples under various stresses and cyclic temperature conditions; research shows that the permeability loss decreases greatly with the increasing number of temperature cycles; [14] suggested that increasing the coalbed temperature will assist matrix stimulation by increasing the diffusion flux, which in turn enhances the well productivity. However, the economic benefit from additional methane is too small to justify the thermal stimulation of the bed. The true benefit of thermal stimulation lies in the enhanced rate of recovery, which results in improving the net present value (NPV) of the produced gas; [15] introduced cryogenic technology into the coalbed methane (CBM) fracturing and puts forward a new cryogenic volume fracturing technology, whose mechanism is alternative injecting water and cryogenic fluid by small rate to freeze the water in the fracture and cleat, temporary plugging fracture to divert, and forming complex fracture networks to increasing CBM production. Moreover, in terms of $\mathrm{CO}_{2}$ displacement technology, some international scholars [16-18] maintain that $\mathrm{CO}_{2}$ flooding can enhance $\mathrm{CH}_{4}$ production, and higher $\mathrm{CO}_{2}$ pressures can drive the $\mathrm{CH}_{4}$ towards the production end with almost $100 \%$ sweep efficiency, and the storage of $\mathrm{CO}_{2}$ in underground coal seams is considered one of the options to reduce the greenhouse gas emissions. Similarly, in terms of hydraulic antireflection technology, hydraulic fracturing technology is a traditional approach to significantly improve the CBM reservoir permeability and CBM extraction rate by injecting high-pressure water into the coal body to promote the fissure development, increase the strain in the coal seam during the mining process, and further make the coal body looser [1921]. For example, [22] proposed the application of a cross- borehole hydraulic slotting technique for preventing and controlling coal and gas outburst disasters during coal roadway excavations. On the basis of Lin et al., [23] demonstrated a novel enhanced coal bed methane recovery (ECBM) extraction technology, which involves the integration of hydraulic slotting (HS) and hydraulic fracturing (HF), and the efficiency of the method is evaluated by a field test. In other respects, the above scholars put forward a lot of permeability enhancement technologies, which have put forward some permeability enhancement mechanism in the research process and also achieved good results in practical application. However, in the process of field practice, there is a lack of means and techniques for accurate quantitative analysis of formation changes. At the same time, some scholars have established the mathematical model of multiphase seepage by numerical simulation, which enriches the theoretical basis for the enhanced extraction of coalbed methane. Moreover, there is a lack of numerical simulation methods that can be directly used to determine the field parameters in the actual application process.

In China, most CBM extractions have been conducted with underground drilling [24]. Accompanied by underground mining processes, the risk of various mine disasters always exists, and hydraulic measures can fracture a coal seam, increase coal seam porosity, improve permeability, resulting in uniform water distribution between the coal seam fracture and pore, and soften and moisten the coal seam. Therefore, the coal seam gas content and coal sample ground stress are reduced, the water content is increased, coal dust is suppressed, and the comprehensive prevention of a mine disaster is achieved. Specifically, in the treatment of coal and gas outburst disasters, the hydraulic flushing drilling technology can not only control the development of fractures in CBM reservoirs by changing hydraulic parameters but also improve the permeability of CBM reservoirs through the reasonable design of borehole layout. However, in the application of hydraulic flushing technology, the mechanical environment and stress-strain characteristics of the coal body will affect the hydraulic flushing effect. Therefore, clarifying the dynamic variation characteristics of the stress and strain of the coal body within the range affected by hydraulic flushing is important for improving the disaster prevention effect and the CBM production efficiency and making it clear how hydraulic flushing relieves pressure, enhances permeability, and prevents disaster. And in the pressure relief process of hydraulic flushing, according to the actual situation of the site, effective positioning of the real pressure relief range is also the key basis of hydraulic flushing technology. Therefore, it is necessary to innovate the accurately determined method of the pressure relief range.

As shown in Figure 1, first, based on the geological characteristics and disaster features of the Linhuan coal mine, using the self-developed gas radial seepage experimental system, the experimental research on the influence of gas pressure and axial pressure on permeability with different diameter boreholes was carried out. By comparing the changes in coal structure characteristics and seepage characteristics around the boreholes under different borehole diameters, the influence of the changes in coal structure before and 


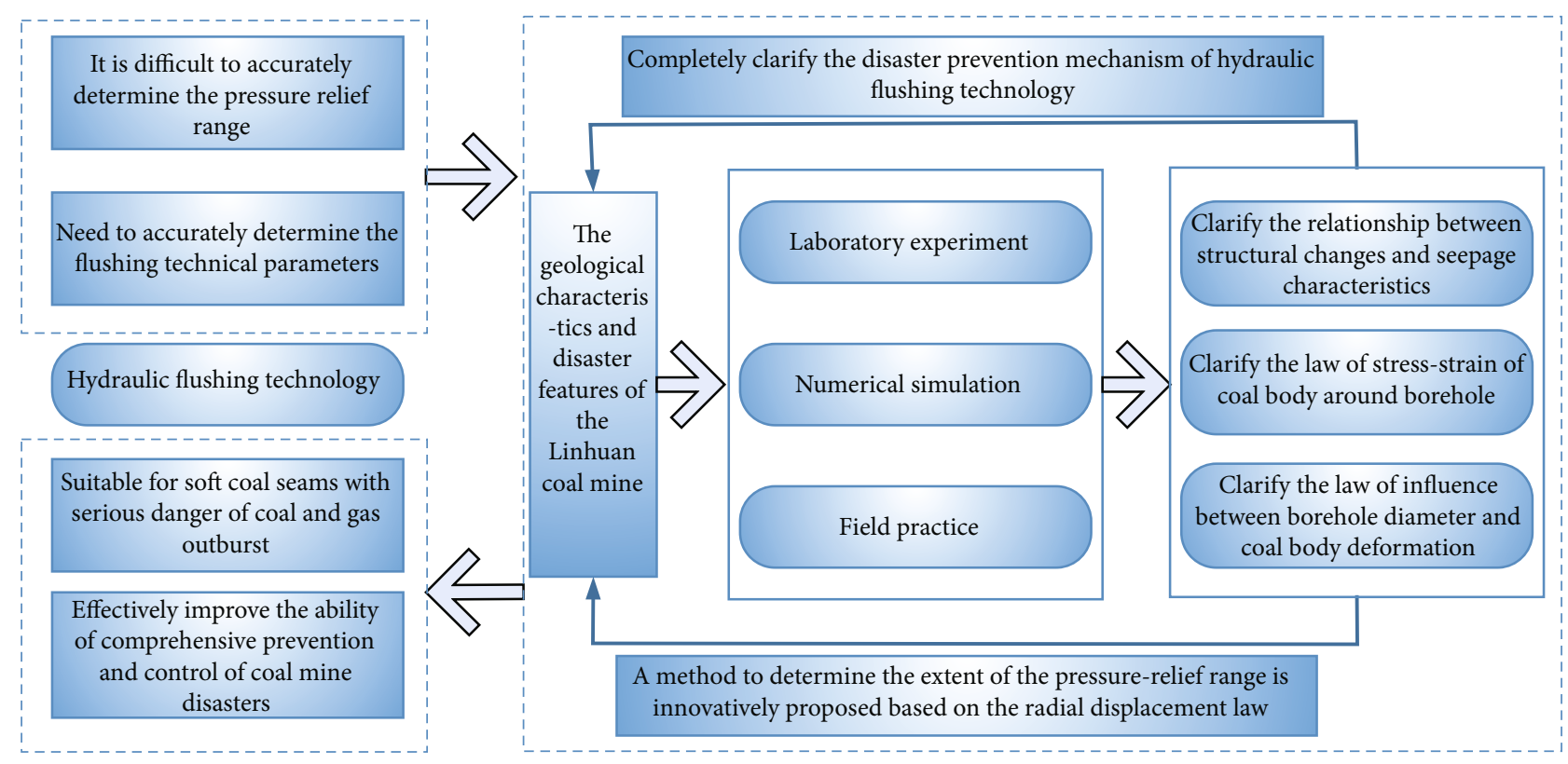

Figure 1: The general sketch of the problem under study.

after hydraulic flushing on seepage characteristics is clear. Then, the stress-strain distribution within the coal surrounding boreholes (of different diameters) is analyzed by numerical calculation, in order to simulate the coal body deformation around the borehole inside the gray system of the real coal seam. Further, the lab experimental and numerical simulation results are used as the theoretical basis for the field experiment; to improve the permeability of coal seam and promote the CBM extraction efficiency, the hydraulic flushing approach for drainage enhancement is proposed. To analyze the influence of the hydraulic flushing approach, we introduce fiber Bragg grating (FBG) sensors and on-line monitoring technology, and the radial strain is taken as an index to indicate the surrounding coal's stress-deformation changing pattern. Finally, with a combination of a lab experiment and numerical simulation, we realize the real inversion of drilling deformation before and after hydraulic punching and clarify the mechanical characteristics that cause such deformation; based on the variation of the permeability and the stress-strain relationship of the coal body around the borehole, the mechanism of pressure relief and disaster prevention of hydraulic flushing is revealed. Based on this mechanism, combined with field practice, a method to determine the extent of the pressure relief range is innovatively proposed based on the radial displacement law.

\section{Coal Mine and Geological Survey}

The Linhuan coal mine is located in Suixi County, southwest of Huaibei City, Anhui Province. The mine is approximately $40 \mathrm{~km}$ from Huaibei City in the north and $30 \mathrm{~km}$ to the east of Suzhou City. The mine is $13 \mathrm{~km}$ long from east to west and $4 \mathrm{~km}$ long from north to south. The area is approximately $50 \mathrm{~km}^{2}$, and its mining capacity is 2.4 million t per year. In the process of mining, as mining depth accumulates, the gas content of the coal seam increases, thereby increasing the amount of gas emission. The major mining seams, coal seam Nr.7, Nr.9, and Nr.10, are all prone to coal and gas outbursts, whose average total thickness registers $7.36 \mathrm{~m}$, with dip angles of $10^{\circ} \sim 15^{\circ}$. The onsite experiment is conducted at working face 9134 (inside), eastern wing, coal seam Nr.9. The coal seam occurrence and the layout of the roadway of this region are shown in Figure 2. The average thickness of working face 9134 (inside) is $2.73 \mathrm{~m}$, with $2.9 \mathrm{~m}$ thick fine sandstone above directly and $4.7 \mathrm{~m}$ thick mudstone underground. Onsite measurement at working face 9134 (inside) demonstrated that the gas pressure is $1.80 \mathrm{MPa}$ and the gas content is $8.92 \mathrm{~m}^{3} / \mathrm{t}$, with initial gas dispersion velocity registering $11.85 \mathrm{mmHg}$. Formal engineering practice shows that the coal body is extremely soft, and the gas pressure is high in this region. In addition, the mining history witnessed a dynamic phenomenon of coal and gas outbursts in the drilling process.

\section{Experiments for Determining the Relationship between Permeability and Boreholes of Different Diameters}

3.1. Experimental Apparatus and Procedure. The experiment system can provide radial steady seepage of gas with an environment of different confining pressures (for the simulation of vertical stress), various gas pressures, and boreholes of different diameters [25]. Figure 3 is a schematic diagram of the system, and the entire system consists of the electric heating unit, high-pressure containers, pressure loading unit, detecting unit (for gas pressure and gas flow), data collecting unit, evacuation unit, and steady gas injection unit. As a water injection device, the SYB06-100 advection pump is produced by Tianjin Science \& Technology Co., Ltd.; its water injection pressure range is $0 \sim 10 \mathrm{MPa}$, and flow range is $0.5 \sim 100 \mathrm{ml} / \mathrm{min}$. As a pressure loading unit, the $50 \mathrm{t}$ small 


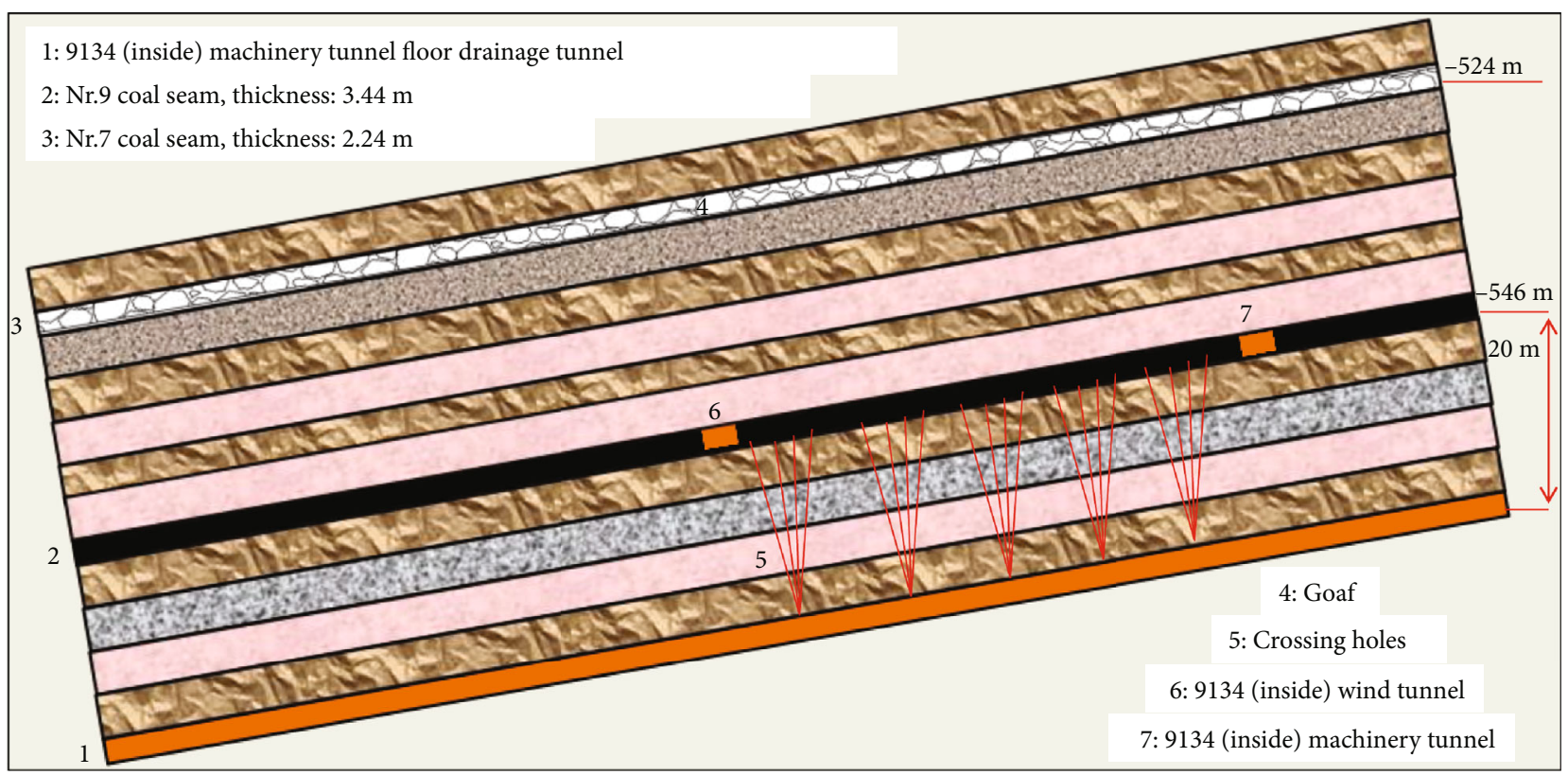

FIgURE 2: Illustration of coal seam occurrence and roadway arrangement in the experimental area.

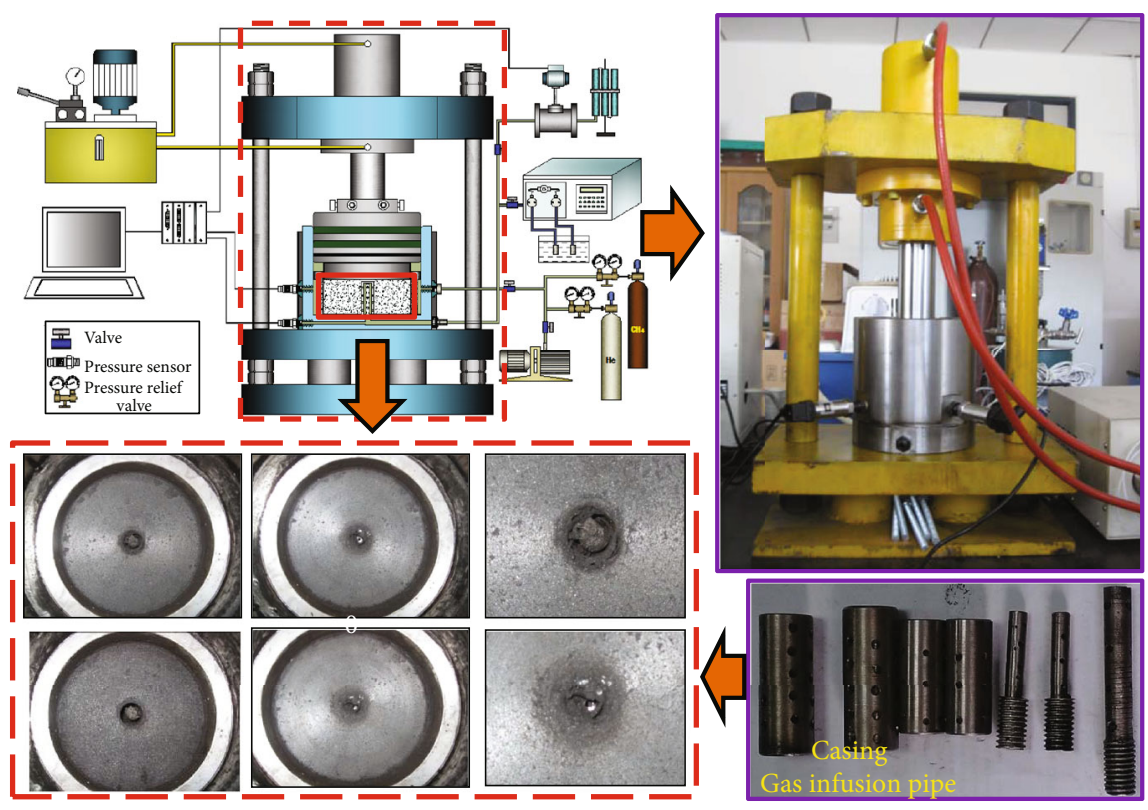

FiguRE 3: Experimental apparatus and deformation characteristics of coal around the boreholes of different diameters.

press is produced by Shandong Dezhou Super Hydraulic Machinery Factory; its pressure range is $0 \sim 100 \mathrm{MPa}$, and stroke is $250 \mathrm{~mm}$. The steady gas injection unit is composed of $99.99 \%$ methane cylinder, high-range pressure reducing valve, quantitative charging tank, precision pressure gauge, high-pressure valve, and connecting pipeline, and as a high range pressure reducing valve, the YQQ-370 hydrogen pressure reducing valve is produced by Shanghai Pressure Regulator Factory Co., Ltd.; its maximum input pressure is $25 \mathrm{MPa}$, and its maximum output pressure is $6 \mathrm{MPa}$. The pre- cision pressure gauges are manufactured by China Reda Instrument Co., Ltd.; their measuring range is $0 \sim 10 \mathrm{MPa}$, and accuracy class is $0.25 \%$. As a pressure sensor and data acquisition device, the CYB-type pressure sensor's standard range is 0 to $10 \mathrm{MPa}$, accuracy is $0.2 \%$, and response time $\leq 1 \mathrm{~ms}$. The data acquisition device is installed with an I555 series static/dynamic data acquisition system provided by Shanghai Yicheng Test Equipment Co., Ltd.; its device's analog input voltage signal ranges from $\pm 0.1 \mathrm{~V}$ to $\pm 10 \mathrm{~V}$, and data acquisition frequency registers $1000 \mathrm{~Hz}$. 
The permeability of the coal sample under specific vertical pressure can be calculated by using

$$
k=\frac{Q_{0} \mu p_{0} \ln \left(\sqrt{r_{e} / r_{w}}\right)}{\pi h\left(p_{e}^{2}-p_{w}^{2}\right)},
$$

where $k$ is the permeability of the coal sample $\left(10^{-3} \mu \mathrm{m}^{2}\right) ; \mu$ is the gas viscosity $\left(1.087 \times 10^{-5} \mathrm{~Pa} \cdot \mathrm{s}\right.$ when the temperature registers at $\left.20^{\circ} \mathrm{C}\right) ; p_{0}$ represents the laboratory atmospheric pressure $(\mathrm{Pa}) ; Q_{0}$ is the gas flow $(\mathrm{ml} / \mathrm{s}) ; P_{w}$ and $P_{e}$ represent the pressures of the inner and exterior boundaries, respectively $(\mathrm{MPa}) ; r_{w}$ and $r_{e}$ represent the radii of the inner and exterior boundaries, respectively $(\mathrm{cm})$; and $h$ is the height of the coal seam $(\mathrm{cm})$.

In order to study the characteristics of gas seepage, particles with a particle size of $0 \sim 0.5 \mathrm{~mm}$ are selected as samples. The industrial analysis of coal samples is shown in Table 1. To achieve different borehole diameters in radial seepage experiments, preinstall the casing on the gas infusion pipe of different pore diameters, fill the cotton yarn between the casing and the gas infusion pipe, then weigh $0.90 \mathrm{~kg}$ of coal into the high-pressure tank, start the press, apply $12 \mathrm{MPa}$ original vertical stress, and stabilize for $4 \mathrm{~h}$; after the casing is taken out, a free surface of the coal body forms in the borehole; adjust the vertical stress again, after each vertical stress adjustment, turn on the data collecting unit, and adjust the vertical stress and gas pressure to the set value. After adsorbing the gas for 4 hours, open the valve for gas release. After the gas flow is stabilized after being released for 20 minutes, the flow test result in the data collecting unit is recorded. The outer diameter of the experimental casing is $\Phi 18 \mathrm{~mm}$, and the diameter of the gas infusion pipe is $\Phi 7 \mathrm{~mm}$.

3.2. Experimental Results. As shown in Figure 4 on the relationship curves of permeability and gas pressure and overburden pressure in different diameter boreholes, it can be seen that with the large diameter borehole formed after the casing is installed, the measured permeability decreases with the increase of the vertical stress; under the vertical stress of $4 \sim 8 \mathrm{MPa}$, the permeability measured by the large diameter borehole is higher than that measured by the small diameter borehole formed when the casing is not installed, and the difference is gradually reduced with the increase of the vertical stress; when the vertical stress is higher than $10 \mathrm{MPa}$, the permeability change curves overlap. At the same time, the permeability decreases with the increase of the gas pressure and tends to be stable. In the low vertical stress stage, the permeability measured by the large diameter borehole is relatively high.

The experimental results show that as the borehole diameter increases, the permeability of the coal around the borehole increases significantly, but the tendency of the increase in permeability decreases with increasing vertical stress. The reason is that as the borehole diameter increases, the exposed free surface of the borehole increases; during the vertical stress loading process, the coal surrounding the borehole experienced four processes of primary stress, concentrated stress, peak stress, and residual stress. The concentrated stress and the peak stress produce the largest secondary stress
TABLE 1: Industrial analysis values of experimental coal sample.

\begin{tabular}{lccc}
\hline $\begin{array}{l}\text { Ash } A_{\mathrm{d}} \\
(\%)\end{array}$ & $\begin{array}{c}\text { Moisture } M_{\text {ad }} \\
(\%)\end{array}$ & $\begin{array}{c}\text { Volatile } V_{\text {daf }} \\
(\%)\end{array}$ & $\begin{array}{c}\text { True density } \\
\left(\mathrm{g} / \mathrm{cm}^{3}\right)\end{array}$ \\
\hline 29.25 & 1.28 & 26.06 & 1.46 \\
\hline
\end{tabular}

at the boundary of the borehole, which in turn causes the shear failure of the coal body, and the partial pressure of the coal body is transferred to the adjacent external coal body unit; the external coal body unit begins to experience the concentrated stress and peak stress stage; the shear failure coal body still bears part of the stress, that is, residual stress; the residual stress area after the failure is the borehole pressure relief area' under the secondary stress shear failure, the coal body expands and deforms towards the center of the borehole, and the deformation is mainly plastic deformation; the low-strength soft coal body is mainly creeping, which causes the free surface of the borehole to gradually shrink; for high-strength coal bodies, when the plastic deformation is higher than the ultimate deformation, brittle failure such as hole collapse occurs. The coal sample in this experiment is a soft coal body with low strength and mainly creep deformation. The distribution form of the coal around the borehole before and after creep is shown in Figure 3. During the experiment, as the vertical stress increases after taking out the casing, the range of the coal pressure relief area around the free surface of the borehole is expanded, and the permeability of the coal body is generally higher than that measured by the casing installed; with the increase of vertical stress, the free surface of the coal body gradually decreases, and the increasing trend of the pressure relief range is weakened, the residual stress of the coal body in the pressure relief area is gradually increased, and the coal body permeability gradually approaches the case where the casing is not installed; because the borehole diameter of this experiment is relatively small, the area of pressure relief is limited. When the vertical stress is higher than $10 \mathrm{MPa}$, the effect of creep pressure relief of coal near the borehole is much smaller than that of high vertical stress, thus resulting in the permeability change curves overlapping.

\section{Analysis of Numerical Simulation}

4.1. Model Construction. To further deconstruct the stress distribution characteristics of coal around the boreholes of different diameters, we introduced the Mohr-Coulomb constitutive model for numerical simulation using FLAC ${ }^{3 \mathrm{D}}$ software based on the background of coal seam Linhuan Nr.9. Based on the measured results, the coal's mechanical parameters for numerical simulation are listed in Table 2. As shown in Figure 5, the model size is $10 \mathrm{~m} \times 10 \mathrm{~m} \times 4 \mathrm{~m}$ (length $\times$ width $\times$ thickness). The uniform load was applied at the top of the model, and the vertical stress was 14.5 $\mathrm{MPa}$, which simulated the self-weight of the overlying rock mass. Under the conditions of deep high ground stress, the original rock was in a quasihydrostatic pressure state [26], following the Heim hypothesis. In addition, the model 


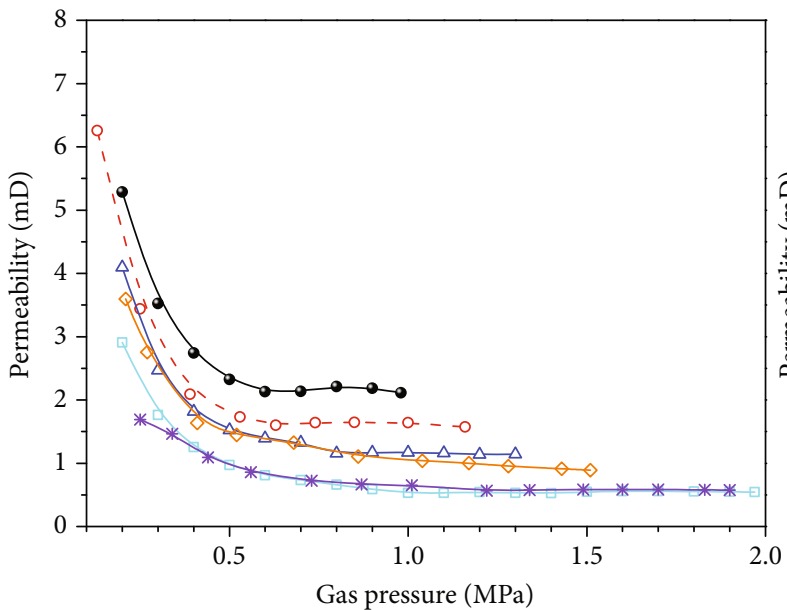

$\multimap$ Overburden pressure, $4 \mathrm{MP}$, diameter of the borehole, $18 \mathrm{~mm}$
$-\_$Overburden pressure, $4 \mathrm{MPa}$, diameter of the borehole, $7 \mathrm{~mm}$
$-\triangle-$ Overburden pressure, $8 \mathrm{MPa}$, diameter of the borehole, $18 \mathrm{~mm}$
$\multimap-$ Overburden pressure, $8 \mathrm{MPa}$, diameter of the borehole, $7 \mathrm{~mm}$
$-\square$ Overburden pressure, $12 \mathrm{MPa}$, diameter of the borehole, $18 \mathrm{~mm}$
$\rightarrow-$ Overburden pressure, $12 \mathrm{MPa}$, diameter of the borehole, $7 \mathrm{~mm}$

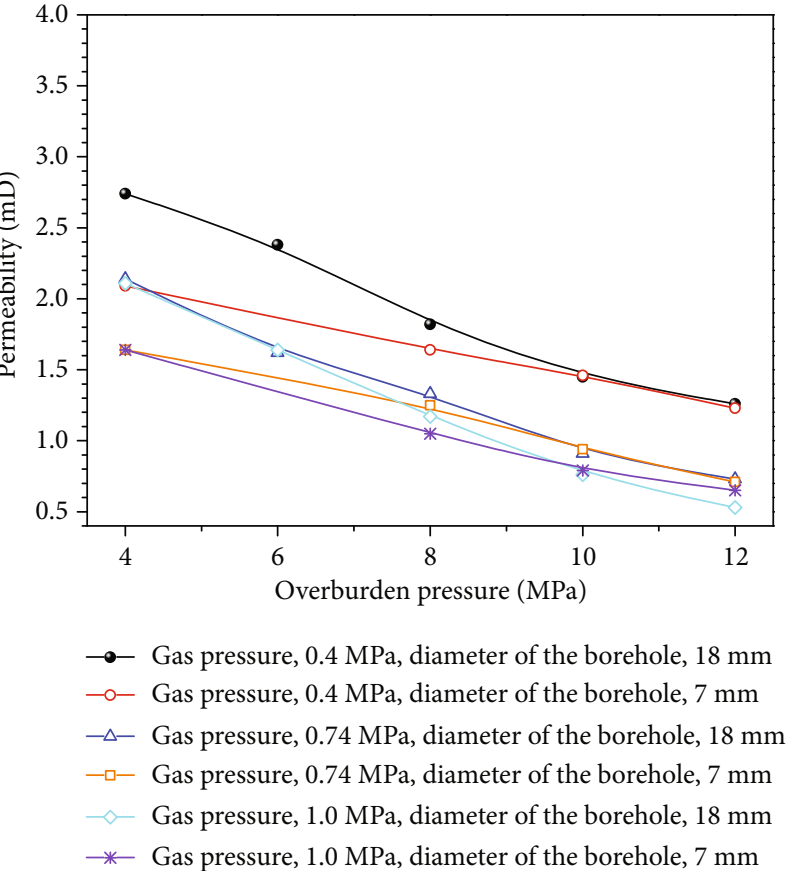

FIGURE 4: Relationship curves of permeability and gas pressure and overburden pressure in different diameter boreholes.

TABLE 2: Physical-mechanical parameters of the coal body.

\begin{tabular}{lcccccc}
\hline Category & $\begin{array}{c}\text { Volumetric } \\
\text { weight }\end{array}$ & $\begin{array}{c}\text { Bulk modulus } \\
(\mathrm{GPa})\end{array}$ & $\begin{array}{c}\text { Shear modulus } \\
(\mathrm{GPa})\end{array}$ & $\begin{array}{c}\text { Tensile strength } \\
(\mathrm{MPa})\end{array}$ & $\begin{array}{c}\text { Adhesion } \\
(\mathrm{MPa})\end{array}$ & $\begin{array}{c}\text { Internal friction angle } \\
\left({ }^{\circ}\right)\end{array}$ \\
\hline Coal seam & 1400 & 0.47 & 0.23 & 0.58 & 0.40 & 16 \\
\hline
\end{tabular}

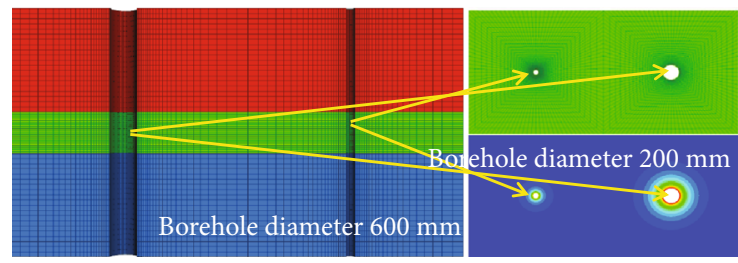

Figure 5: Geometric model of numerical simulation.

bottom boundary is fixed, and the diameters of boreholes are $160 \mathrm{~mm}$ and $579 \mathrm{~mm}$, respectively.

4.2. The Approach to Characterizing Borehole's Radial Line Strain. As shown in Figure 6, during the drilling process, the cylindrical area around the borehole remains in the plastic equilibrium state and is further transformed into the destructive state [27]. The stress of the surrounding coal evolves from the original stress to the concentrated stress, the peak stress, and the residual stress. In addition, shear failure of the coal body emerges and moves into the drilling center in the radial direction $[28,29]$; the deformation of the surrounding coal can be featured by microelement radial displacement and radial line strain. For the radial displacement law before drilling, the state of the microelement, $M$, is shown in Figure 6, and the boundaries of the microelement,
$M$, in the radial direction are points $A$ and $B$. After the completion of drilling, as the stress of the coal around the borehole is redistributed, the microelement is shifted along the direction of drilling and finally transformed into a new state, $m$. Meanwhile, the corresponding microelement boundaries move to points $a$ and $b$, which is the radial displacement law. The amount of radial displacement of the microelement boundary node is as follows:

$$
\left\{\begin{array}{l}
\Delta l_{A}=l_{a}-l_{B} \\
\Delta l_{B}=l_{b}-l_{B} .
\end{array}\right.
$$

The strain of microelement along the radial line is as follows:

$$
\varepsilon=\frac{\Delta l_{M}}{l_{M}}=\frac{\Delta l_{A}-\Delta l_{B}}{l_{A}-l_{B}}=\frac{\left(l_{a}-l_{A}\right)\left(l_{b}-l_{B}\right)}{l_{A}-l_{B}},
$$

where $\varepsilon$ is the strain of microelement along the radial line; $l_{A}, l_{B}, l_{a}$, and $l_{b}$ are the distance from the borehole center to the respective microelement nodes.

4.3. Numerical Simulation Results. Three-dimensional calculation models of the stress and the deformation of coal body around boreholes under two different diameters $(200 \mathrm{~mm}$ 


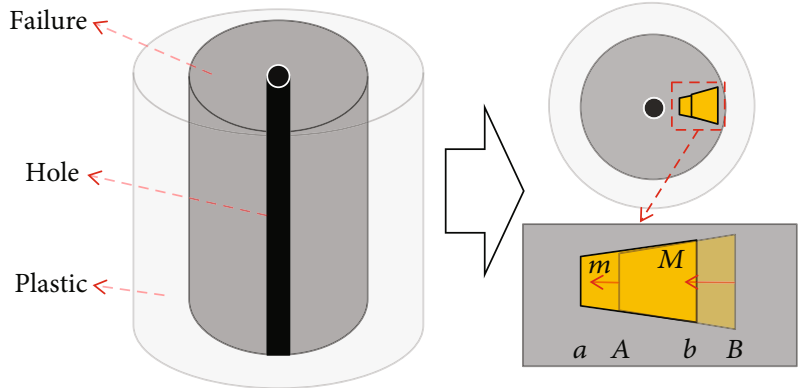

FIgURE 6: Radial line strain of the microelement around the borehole.

and $600 \mathrm{~mm}$ ) were established. Figure 7 shows the distribution curve of the maximum principal stress, radial displacement, and radial line strain of coal around the boreholes with diameters of $200 \mathrm{~mm}$ and $600 \mathrm{~mm}$.

It is generally accepted $[7,30]$ that during stress evolution, the destroyed coal will move to the center of the borehole and cause deformation. As shown in Figure 7, because of the failure-deformation of the coal around boreholes, the bearing strength decreases, and the stress distribution can be classified as a pressure relief area, a stress concentration area, and an original stress area. As seen from Figure 7, the maximum radial line strain of coal around the borehole with a diameter of $600 \mathrm{~mm}$ is approximately 3.66 times of the maximum radial line strain of the borehole $200 \mathrm{~mm}$ in diameter. Moreover, the radial line strain increases as coal approaches the borehole, reflecting the coal's pressure relief degree. And larger diameter leads to a bigger pressure relief area; therefore, combined with the experimental results, it can be found that as the borehole diameters increases, the permeability increases. The above experimental and numerical analysis results provide a rich theoretical basis for the field experiment of hydraulic flushing technology.

\section{Field Experiment of Hydraulic Flushing}

5.1. The System and Technology of Hydraulic Flushing. During the drilling process, the hydraulic flushing system shown in Figure 8 is used for hydraulic drilling in coal seam high-pressure hydraulic flushing, thereby increasing the borehole's equivalent pore diameter and fully unloading the surrounding coal's ground stress. Therefore, the permeability of the coal around the borehole is improved, thereby increasing the CBM extraction efficiency. Overall, the maneuver helps reduce the CBM content and lowers the risk of coal and gas outbursts [31]. As shown in Figure 8, the hydraulic flushing system is composed of a hydraulic drilling rig, a high-pressure water pump, an antioutburst device, a coal/water discharge device, an extraction pipe, and a hydraulic flushing drill.

The concrete construction process is as follows.

First, a borehole with a diameter of $160 \mathrm{~mm}$ and a depth of 3 meters was constructed in the rock strata floor roadway drilling field. Then, place the casing in the drill hole and temporarily fixate it with a cork stopper and then fill the quick-drying cement between the casing and the hole wall, and the cement was allowed to solidify for one hour, and the drill rig continues the drilling process through the casing. Afterward, the cross joint was connected for the coal/water discharge device with flanges, and then, the drilling was continued through the cross joint to $0.5 \mathrm{~m}$ beneath the floor of coal seam. Next, the cross joint's two outlets were connected-one to the extraction pipe and the other to the antioutburst device, and the coal/water discharge device was installed at the end of borehole. Drilling continued, and the coal seam was penetrated until the borehole was $0.5 \mathrm{~m}$ into the roof. The coal seam was penetrated once more with a specialized drill equipped with a hydraulic flushing system. During this process, the water pressure remained stable within the first $1 \mathrm{~m}$ of drilling and then was replaced with $12 \mathrm{MPa}$ high pressure, at the subsequent drilling stage for coal flushing up and down repeatedly. During this stage, the drill bit rotation drove high-pressure water at the side wing outlet to crush the surrounding coal body. Next, the crushed coal was transmitted to the outlet of the borehole until it went into the antioutburst device. Once the water that flows out of the borehole became crystal, static water and high-pressure water were utilized in turn for coal flushing, and the drilling process continued until the coal seam was penetrated before the drill pipe was finally withdrawn. During the process of hydraulic flushing, the gas in the antioutburst device and coal discharge outlet was extracted in time, so the coal and water in the antioutburst device were cleaned. The cleaned coal was then bagged for weighing. The amount of methane discharged during the process can be calculated based on the amount of extracted gas. Moreover, to prevent gas emission anomalies and excessive methane concentration caused by multiple borehole construction, we constructed boreholes in the form of columns and timely sealed the boreholes of every column adjacent to the gas gathering-drainage device accessed for joint extraction.

\subsection{Radial Deformation Law Analysis}

5.2.1. FBG Sensor System and Monitoring Plan. This fiber grating displacement sensor adopted in this paper has a diameter of $10 \mathrm{~mm}$ and a length of $1 \mathrm{~m}$ with two different measuring ranges of $10 \mathrm{~cm}$ ( $1 \mathrm{set}$ ) and $5 \mathrm{~cm}$ ( $3 \mathrm{sets}$ ). In addition, a displacement monitoring system, which collects and records data every 2 seconds, based on FBG sensors, is designed. The system consists of a portable FBG demodulator, fiber grating strain sensors, transmission fibers, and so on. The fiber grating strain sensors are used to monitor the radial line strain occurring in the coal surrounding boreholes. Moreover, to avoid the sensors being damaged when burying the coal structure through the borehole, they are cased with tubular flexible material with both ends clamped, and the temperature probe is used for measuring the results of error correction. The test wavelength data are substituted into equation (4) to calculate the radial displacement of each measuring point. The fiber grating experimental system is shown in Figure 9:

$$
D=K_{S}\left[\left(P_{s}-P_{0}\right)-K_{T}\left(T-T_{0}\right)\right]
$$



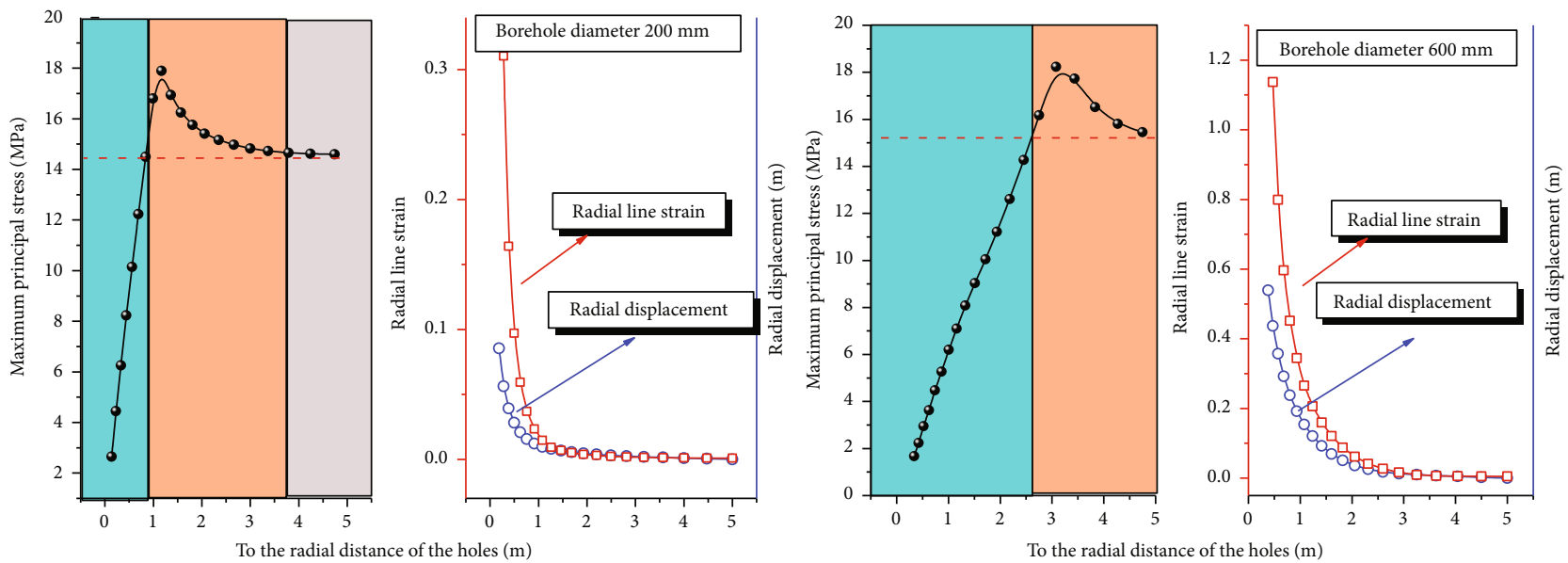

FIGURE 7: Distribution curve of the maximum principal stress, radial displacement, and radial line strain of coal around the boreholes.

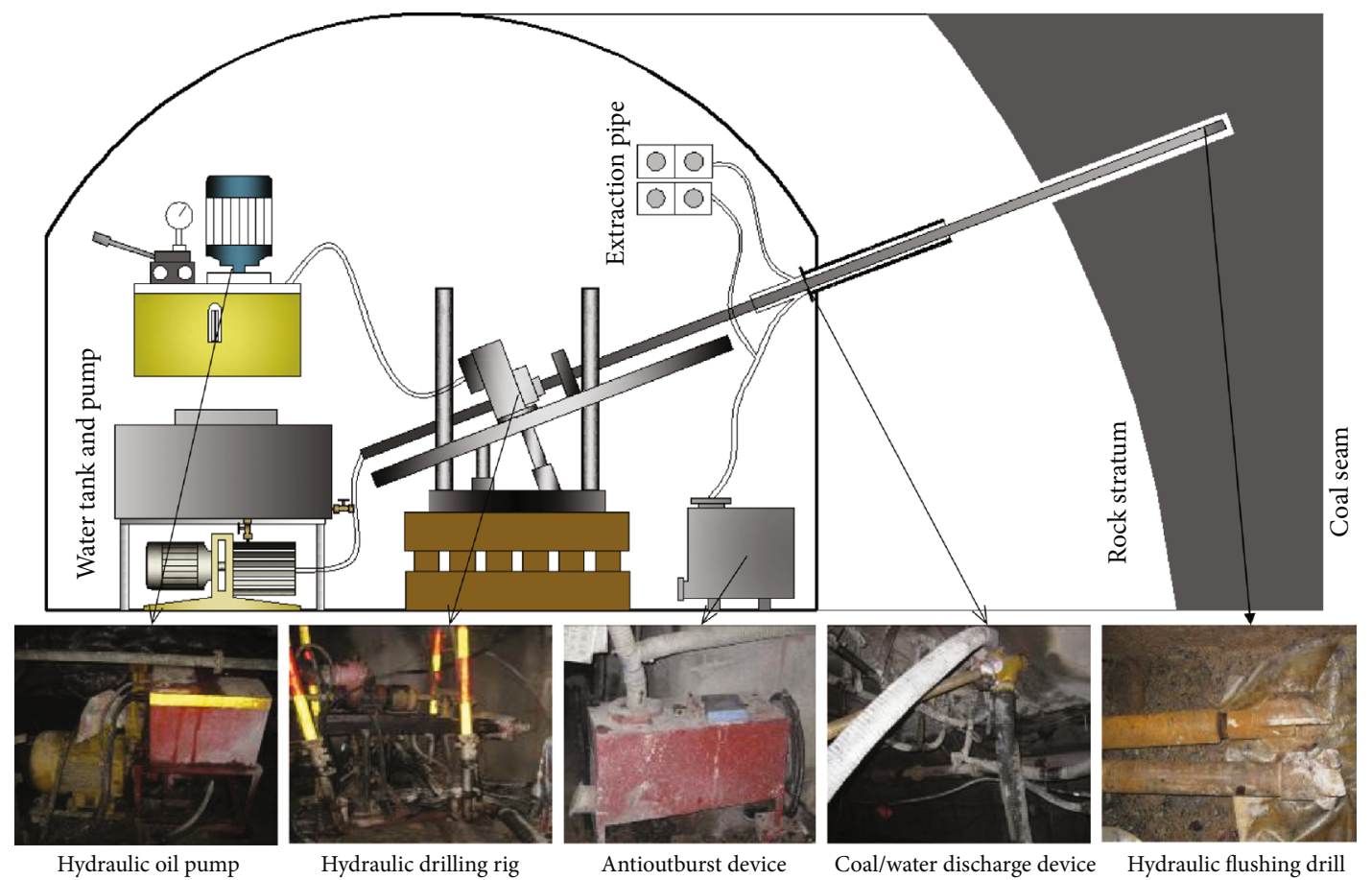

FIGURE 8: The system for the construction of the crossing borehole adopting hydraulic flushing.

where $D$ is the displacement of the fiber grating $(\mathrm{mm}) ; K_{s}$ is the coefficient of sensor displacement/wavelength $(\mathrm{mm} / \mathrm{nm})$; $K_{T}$ is the temperature correction coefficient, wavelength shift/temperature $\left(\mathrm{nm} /{ }^{\circ} \mathrm{C}\right) ; K_{s}$ and $K_{T}$ are the constants for the specified sensor; $P_{0}$ is the initial value of the wavelength of the fiber grating $(\mathrm{nm}) ; P_{S}$ is the wavelength measured after the displacement $(\mathrm{nm}) ; T_{0}$ is the ambient temperature when $P_{0}$ is measured $\left({ }^{\circ} \mathrm{C}\right)$; and $T$ is the ambient temperature when $P_{S}$ is measured.

As shown in Figure 9, prior to the implementation of the hydraulic flushing approach, we construct a bedding borehole in the wind tunnel, working face 9134 (inside) as a test drilling in advance. Once finished, the FBG sensors are banded with $4 \mathrm{~m}$ long PVC pipe in every meter and then laid in the borehole. The FBG sensor at the bottom of borehole is named measuring point no. 1 , followed by measuring point no. 2 , no. 3 , and no. 4 , all of which are separated by one meter. Afterward, cement mortar is injected into the borehole to have the fiber grating be closely attached with the coal body to ensure that the fiber grating moves radially with the coal body as the hydraulic flushing processing, thereby enabling the measurement of coal's displacement. Because of the influence of coal's flowing deformation around the borehole, FBG sensors undergo deformation and transform from the free state to the squeezed state within the process of the layout of FBGs in the bedding borehole and successive borehole grouting. Through the dynamic change of data, the creep of coal around the bedding borehole can be monitored. 


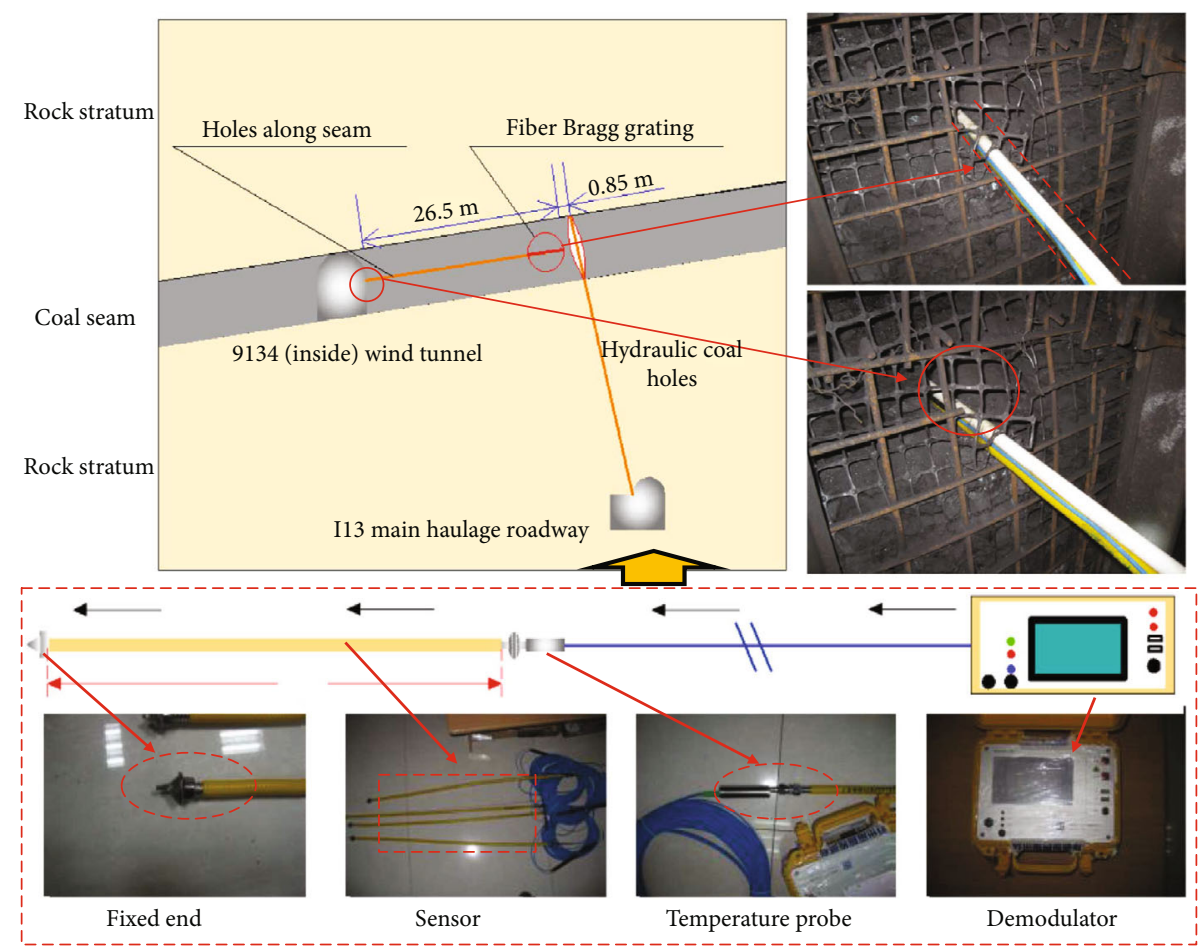

Figure 9: Layout of the fiber grating and fiber grating experimental system.

Until the displacement of FBG sensors become stable, we take the value as the initial displacement. Next, a hydraulic flushing crossing borehole is constructed in the I13 main haulage roadway, and then, the FBG demodulator is turned on for real-time monitoring.

\subsubsection{Radial Displacement Measurement Results. According} to the experimental requirements, after the completion of the borehole down the seam, the fiber grating is laid, and then, the cement mortar is injected into the hole. As shown in Figure 10, the displacement of each measuring point varies markedly within 70 minutes of the installation stabilization stage. The experiment outcomes show that the strain within coal around the borehole is redistributed and deformed after cement mortar injection, which squeezes the surface of the fiber grating sensor, resulting in radial deformation. Thus, it is clear that FBG sensors are sensitive and accurate to the deformation of the object. Therefore, FBG sensors can meet the requirements of experiments. According to monitoring, the radial displacements of FBG sensors tend to be stable after $46 \mathrm{~h}$; therefore, $48 \mathrm{~h}$ after the layout of the fiber grating, the borehole radial displacement value is measured and set as the initial radial displacement value. Specifically, the initial radial displacements of measuring points \#1, \#2, \#3, and \#4 are $0.48 \mathrm{~mm}, 0.53 \mathrm{~mm}, 0.50 \mathrm{~mm}$, and $0.59 \mathrm{~mm}$, respectively.

Afterward, the borehole with an equivalent diameter of $160 \mathrm{~mm}$ was drilled in the I13 main haulage roadway, and the displacement of each measuring point during drilling was monitored in real time. The observation results within 150 min drilling stage are shown in Figure 10, revealing that the distance of hydraulic displacement drilling \#1 measuring point closest to the radial displacement is the largest, and the distances of the \#2, \#3, and \#4 measuring points exhibit less displacement, indicating that, in the drilling process, in the coal around borehole, radial deformation occurs to the center of the borehole; however, this deformation is only present in the smaller area around the borehole. Two days later, the hydraulic flushing approach is introduced to the construction of crossing drilling, with the equivalent diameter registering $579 \mathrm{~mm}$. The displacement of measuring points \#1, $\# 2$, \#3, and \#4 before hydraulic flushing drilling is $4.53 \mathrm{~mm}$, $2.47 \mathrm{~mm}, 1.40 \mathrm{~mm}$, and $1.02 \mathrm{~mm}$, respectively. Data is collected from the FBG sensors after the implementation of the hydraulic flushing initial stage; Figure 10 shows that once hydraulic flushing drilling is completed, the hole's diameter increases and the coal around the borehole shows the radial movement towards the center of the hole. Accordingly, the fiber grating generates radial stretch and line displacement, or radial displacement occurs along with the radial deformation of the coal body. Immediately after the completion of drilling, the radial displacement of the fiber grating continues to increase over time and finally stabilizes. Within 10 days after the completion of hydraulic flushing drilling, the radial displacement of fiber gratings also increases initially and then stabilizes at $40.47 \mathrm{~mm}$, $15.78 \mathrm{~mm}, 3.24 \mathrm{~mm}$, and $1.92 \mathrm{~mm}$.

\section{Discussion}

6.1. Field Measurements vs. Numerical Simulation. Taking the distance from the center of each fiber grating to the center of the borehole as the radial position of the coal body unit measured by the fiber grating, the radial positions of the coal body units measured by the fiber grating \#1, \#2, \#3, and \#4 

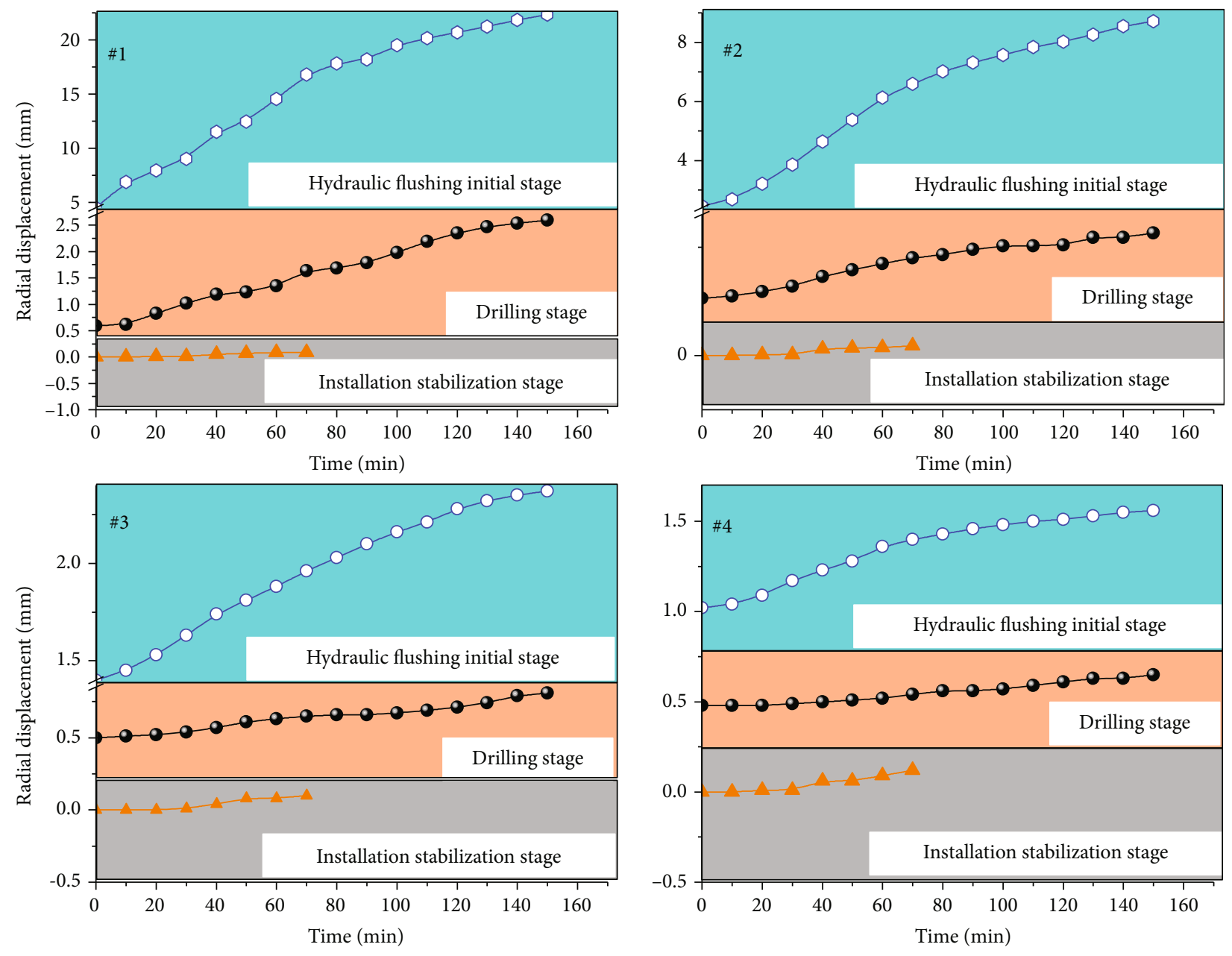

FIgURE 10: Radial displacement within various stages.

are $1.35 \mathrm{~m}, 2.35 \mathrm{~m}, 3.35 \mathrm{~m}$, and $4.35 \mathrm{~m}$, respectively. The radial line strain of a single fiber grating can be obtained by dividing the radial line displacement of the fiber grating by the length of the fiber $(1 \mathrm{~m})$. The borehole of drilling dust extraction with wind-force is $\Phi 160 \mathrm{~mm}$. After 2 days of construction, the radial displacements of measuring points \#1, $\# 2$, \#3, and \#4 are $4.53 \mathrm{~mm}, 2.47 \mathrm{~mm}, 1.40 \mathrm{~mm}$, and $1.02 \mathrm{~mm}$, respectively. The corresponding radial line strains are $0.00453,0.00247,0.0014$, and 0.00102 for measuring points $\# 1, \# 2$, \#3, and \#4, respectively. The borehole of hydraulic flushing drilling is $\Phi 579 \mathrm{~mm}$. After 10 days of construction, the radial displacements of measuring points $\# 1$, \#2, \#3, and \#4 are $40.47 \mathrm{~mm}, 15.78 \mathrm{~mm}, 3.24 \mathrm{~mm}$, and $1.92 \mathrm{~mm}$, respectively, and the corresponding radial line strains are $0.04047,0.01578,0.00324$, and 0.00192 , respectively. After the completion of $\Phi 160 \mathrm{~mm}$ and $\Phi 579 \mathrm{~mm}$ borehole construction, the radial borehole strain distribution is shown in Figure 11.

Figure 11 shows that the radial line strain around the borehole decreases gradually as it goes away from the borehole, and the variation law is consistent with Figure 7 . The negative exponential fit of the radial line strain and radial position results in a quantitative distribution of radial line strain around the hole, given by

$$
\begin{cases}\phi 160 \mathrm{~mm}: \varepsilon=0.01098 e^{-r / 1.32075}=0.00058, & R^{2}=0.996 \\ \phi 579 \mathrm{~mm}: \varepsilon=0.15023 e^{-r / 1.06155}=0.00058, & R^{2}=0.973\end{cases}
$$

Comparison between the measured distribution of the radial strain of coal around the borehole according to equation (5) and its simulated counterpart, obtained as shown in Figure 7, is shown in Figure 12.

Figure 12 reveals that the coal around the holes moves to the center of the hole, causing deformation, regardless of borehole diameter. A difference is found between the measured results and the numerically simulated ones, especially within $2 \mathrm{~m}$ of the borehole; the reason is that the coal body around the borehole not only will bear the pressure of the overlying rock during the actual deformation process but also will be compressed by the uneven load of the surrounding coal body to cause irregular deformation as shown in Figure 3. In the process of numerical simulation, due to the 


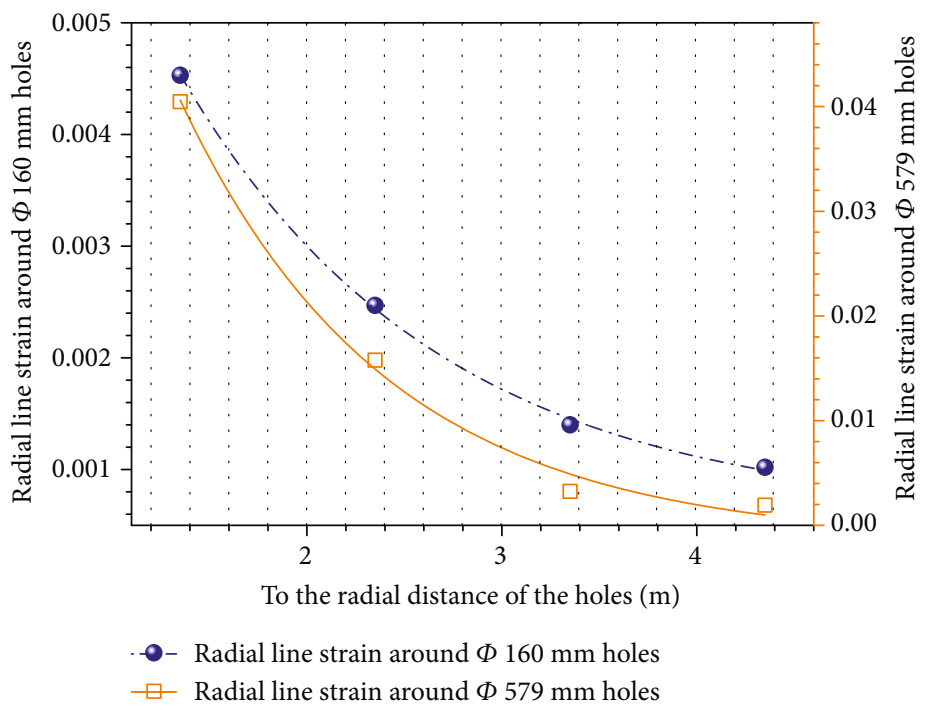

FIGURE 11: Radial line strain distribution of coal around borehole according to onsite measurement with FBG.

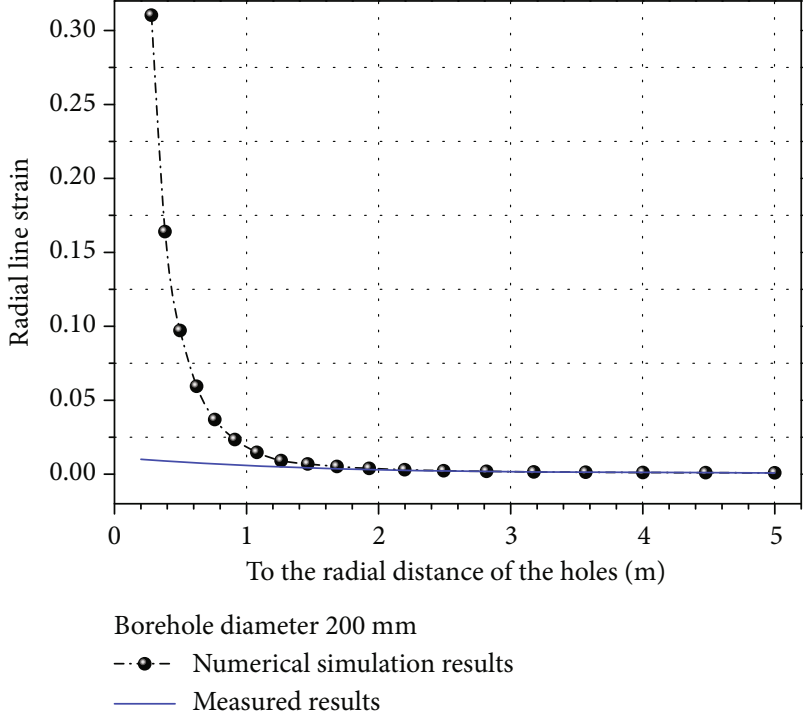

(a)

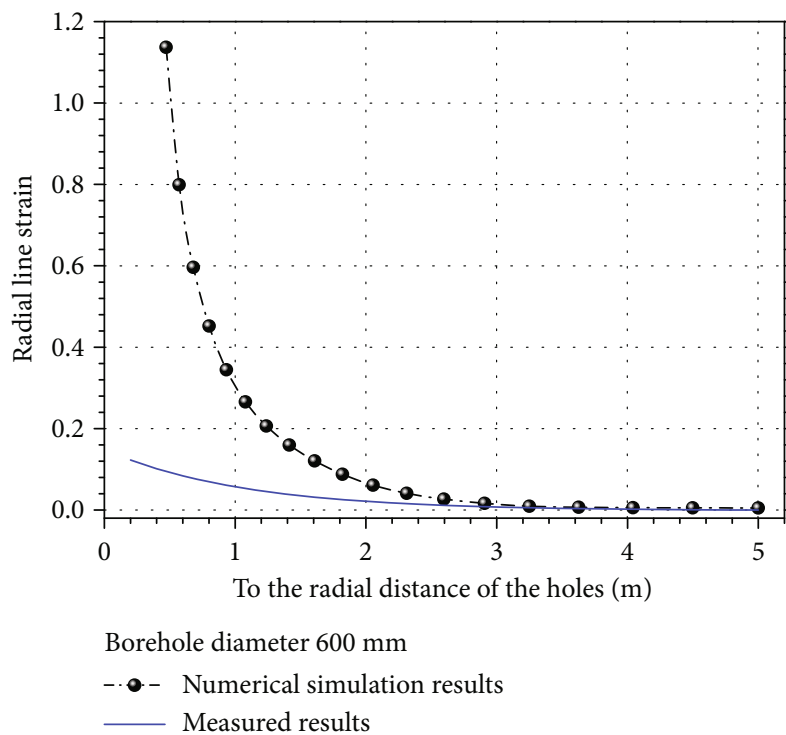

(b)

FIGURE 12: Comparison between curves conducted from onsite measurement and numerical simulation.

uniform load on the simulated coal seam, the deformation amount will increase exponentially in the radial direction of the borehole around the borehole. But the general trend is the same, the closer to the borehole, the greater the radial strain.

\subsection{Borehole Pressure Relief Area Determination Based on the} Radial Line Strain. In this paper, the pressure relief area is defined as an area within which the coal's stress is lower than its original one, and the critical positions of the pressure relief area are radial positions of the borehole where the stress is equal to the original one. Therefore, we propose a method to determine the extent of the pressure relief area on the of basis radial line strain measurement:

(1) Based on the distribution curve of the maximum principal stress in the numerical simulation results in Figure 7, determine the critical positions of the pressure relief area

(2) Based on the radial line strain distribution curve in the numerical simulation results in Figure 7, the radial line strain at the critical position is determined

(3) Substitute the radial line strain values of the microelements at the critical position obtained from numerical 
TABle 3: Drilling effective radius of pressure relief.

\begin{tabular}{lcccc}
\hline $\begin{array}{l}\text { Borehole diameter } \\
(\mathrm{mm})\end{array}$ & $\begin{array}{c}\text { Critical position } \\
\text { (numerical simulation) }\end{array}$ & $\begin{array}{c}\text { Radial line strain } \\
\text { corresponding to critical } \\
\text { position }(\%)\end{array}$ & $\begin{array}{c}\text { Critical position } \\
\text { (onsite measurement) } \\
(\mathrm{m})\end{array}$ & $\begin{array}{c}\text { Pressure relief area } \\
(\text { in diameter) } \\
(\mathrm{m})\end{array}$ \\
\hline 200 & 0.91 & 23.40 & 0.97 & 0.91 \\
600 & 2.59 & 26.78 & 1.77 & 1.77 \\
\hline
\end{tabular}

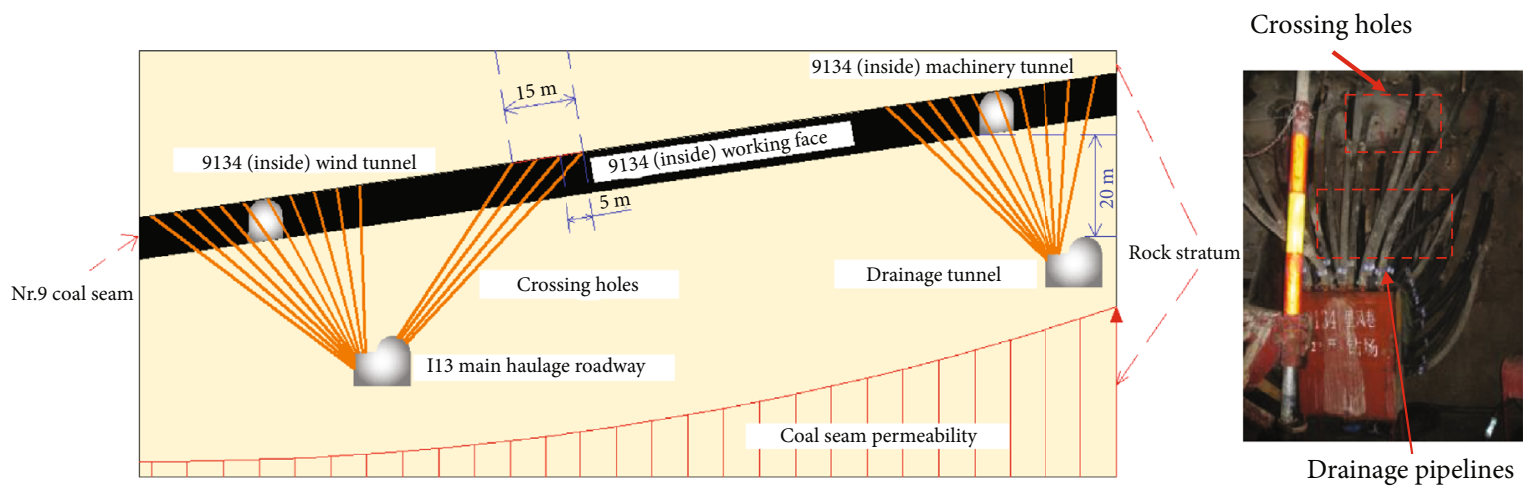

Figure 13: Profile of crossing boreholes in coal of working face 9134 (inside).

simulation using equation (4) and determine critical positions of the measured pressure relief area

(4) Compare the numerical simulation results with the measured one; for the sake of safety, choose the smaller value as the actual drilling pressure relief area

Through this method of combining the field measurements and the numerical simulation, the pressure relief area of boreholes with different diameters can be drawn, as shown in Table 3.

Table 3 reveals that with the increase of the borehole diameter, the radial line strain of the coal body around the borehole increases, as with the effective pressure relief area. The results based on radial line strain show that the effective relief radius expands $0.86 \mathrm{~m}$ once adopting the $\Phi 579 \mathrm{~mm}$ hydraulic flushing borehole compared to its $\Phi 160 \mathrm{~mm}$ counterpart. The measured results show that the larger diameter hydraulic flushing borehole can significantly increase the pressure relief area and reduce coal seam's original stress and thereby reduce its outburst risk and the necessity for antioutburst borehole construction.

\subsection{Error Analysis}

(1) Regarding the setup of boundary conditions for numerical simulation, the original rock stress is estimated by counting the weight of each rock formation, which is different from the actual original rock stress. In addition, the selection of the Mohr-Coulomb model as the constitutive model of coal and rock mass is not totally accurate in elaborating the actual condition

(2) Limited by onsite conditions, we did not set many measuring points with fiber Bragg gratings for the cable, and the PVC pipes are too thick to lay more measuring points while ensuring their precision of position at the same time. The radial strain at each position represents the average radial strain of the $1 \mathrm{~m}$ long coal body where the fiber grating is located. Although the simulation results in the smaller size of the microelements around the borehole can represent the radial line strain of each point in borehole's radial direction, onsite measurements are conducted 10 days after the finish of the drilling process. Because of the influence of the creep deformation of the coal body around the borehole, 10 days is usually shorter than the time actually required to achieve equilibrium. Therefore, the measured results differ from those obtained from the numerical simulation values in this aspect

6.4. The Effect of Permeability Enhancement. According to the abovementioned geological and engineering practices of the experimental area, CBM extraction is meant to be conducted in this area. Specifically, working tunnels and gas extraction tunnel underground ( $20 \mathrm{~m}$ away from the surface of the floor vertically) are constructed at working face 9134 (inside). Next, a drilling field in a rock tunnel is built every $30 \mathrm{~m}$. Finally, a perforated mesh drilling $(5 \mathrm{~m} \times 5 \mathrm{~m})$ drilling field located under the floor is constructed. Once completed, the boreholes are sealed, and CBM extraction begins within the band area of $15 \mathrm{~m}$ on both sides of the wind tunnel, the machinery tunnel, and the open-off cut. In addition, CBM extraction from the wind tunnel is conducted with the help of the borehole starting from the I13 main haulage roadway, and CBM extraction from the machinery tunnel is conducted with the help of the borehole starting from the drainage tunnel; the layout of the upward crossing borehole CBM extraction craft is shown in Figure 13. 


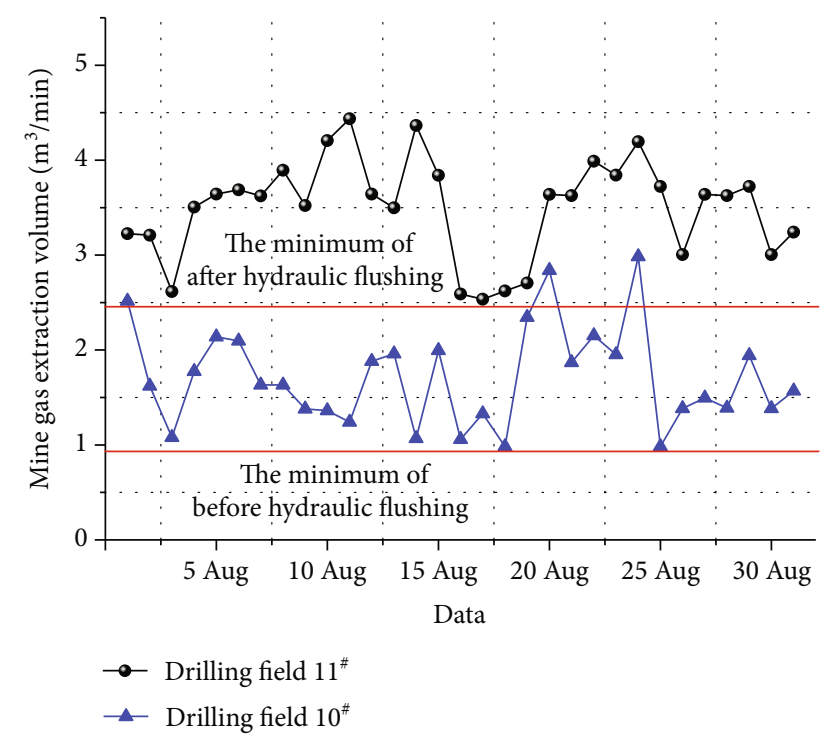

FIGURE 14: Comparison of CBM extraction amount in different drilling sites.

By installing a flow meter in the gas drainage pipeline to calculate the gas drainage volume, and further comparing and analyzing CBM extraction amount after drilling with and without a hydraulic flushing approach, the influence of drilling-inducted pressure relief on CBM emission is obtained. After the difference between CBM extraction amount of drilling fields \#10 and \#11 from that of the main haulage roadway I13 is examined, Figure 14 reveals that the borehole's equivalent diameter of drilling field \#11 is 2 to 3 times that of \#10 and 1.2 times the average CBM extraction amount. During the excavation of the working face, some measurements show that the amount of drill cuttings in the area controlled by drilling field \#11 is significantly lower than that in the area controlled by drilling field \#10. All of these data indicate that hydraulic flushing drilling can effectively reduce the original stress of coal seam. The amount of drill cuttings is often used in underground mines to predict the risk of coal seam gas outbursts and the effect of regional outburst prevention. This index can reflect the distribution of in situ stress in front of the working face and the characteristics of coal strength. That is, the amount of drill cuttings is positively correlated with coal strength and stress, in addition, according to relevant studies [32] and the permeability test results under different overburden pressures, the permeability of coal seam is related to the stress state of the coal seam; therefore, the field experimental results above show that hydraulic flushing can be used to not only expand the hole diameter but also promote pressure relief of the coal body. In summary, the field experiment results are consistent with the experimental and numerical simulation results. That is, by using the hydraulic flushing technology to expand the borehole diameters, the elastic potential in the coal seam and the surrounding rock can be greatly released to achieve regional outburst reduction. In addition, it can significantly improve both the permeability of the coal seam and the CBM extraction rate.

\section{Summary and Conclusions}

(1) When the hydraulic flushing drilling is completed, the hole's diameter increases and the coal around the borehole shows the radial movement towards the center of the hole. Accordingly, the fiber grating generates radial stretch, and line displacement, or radial displacement, occurs along with the radial deformation of the coal body. Immediately after the completion of drilling, the radial displacement of the fiber grating continues to increase over time and finally stabilizes

(2) The maximum radial line strain of coal around the borehole with the diameter of $600 \mathrm{~mm}$ is approximately 3.66 times of the maximum radial line strain of the borehole $200 \mathrm{~mm}$ in diameter. Moreover, the radial line strain increases as coal approaches the borehole, reflecting the coal's pressure relief degree. And larger diameter leads to a bigger pressure relief area

(3) The effective relief radius expands $0.86 \mathrm{~m}$ once adopting the $\Phi 579 \mathrm{~mm}$ hydraulic flushing borehole compared to its $\Phi 160 \mathrm{~mm}$ counterpart. The measured results show that the larger diameter hydraulic flushing borehole can significantly increase the pressure relief area and reduce coal seam's original stress and thereby reduce its outburst risk and the necessity for antioutburst borehole construction

(4) In the practice of hydraulic flushing in the gas-bearing coal seam, it is a process of gas-liquid-solid threephase coupling. Therefore, in the future research process, it is still necessary to further improve the related research methods to more accurately determine the pressure relief range of hydraulic flushing

\section{Nomenclature}

$k$ : The permeability of the coal sample

$\left(10^{-3} \mu \mathrm{m}^{2}\right)$

$\mu$ : $\quad$ The gas viscosity $\left(1.087 \times 10^{-5} \mathrm{~Pa} \cdot \mathrm{s}\right.$ when

the temperature registers at $20^{\circ} \mathrm{C}$ )

$p_{0}$ : The laboratory atmospheric pressure $(\mathrm{Pa})$

$Q_{0}$ : $\quad$ The gas flow $(\mathrm{ml} / \mathrm{s})$

$P_{w}$ and $P_{e}: \quad$ The pressures of the inner and exterior

$r_{w}$ and $r_{e}: \quad$ The radii of the inner and exterior bound-

aries, respectively $(\mathrm{cm})$

$h: \quad$ The height of the coal seam $(\mathrm{cm})$

$\varepsilon$ : The strain of microelement along the radial line

$l_{A}, l_{B}, l_{a}$, and $l_{b}$ : The distance from borehole center to the respective microelement nodes

D: $\quad$ The displacement of the fiber grating $(\mathrm{mm})$

$K_{s}$ : The coefficient of sensor displacement/wa-

$K_{T}: \quad$ velength $(\mathrm{mm} / \mathrm{nm})$ wavelength shift/temperature $\left(\mathrm{nm} /{ }^{\circ} \mathrm{C}\right)$

$K_{s}$ and $K_{T}$ : The constants for the specified sensor 


$$
\begin{array}{ll}
P_{0}: & \text { The initial value of the wavelength of the } \\
& \text { fiber grating }(\mathrm{nm}) \\
& \text { The wavelength measured after the dis- } \\
P_{S}: & \text { placement }(\mathrm{nm}) \\
& \text { The ambient temperature when } P_{0} \text { is mea- } \\
T_{0}: & \text { sured }\left({ }^{\circ} \mathrm{C}\right) \\
& \text { The ambient temperature when } P_{S} \text { is } \\
& \text { measured. }
\end{array}
$$

\section{Data Availability}

The research data used to support the findings of this study may be released upon application to the corresponding author. Some or all data, models, or code generated or used during the study are available from the corresponding author by request (experimental equipment parameters, laboratory experimental result data, field experimental results, etc.).

\section{Conflicts of Interest}

The authors declare that there is no conflict of interest regarding the publication of this paper.

\section{Acknowledgments}

The authors would like to acknowledge the support of the National Natural Science Foundation of China (52074173, 51604168, and 51934004), Key Research and Development Plan of Shandong Province, China (2019GSF111033), Major Program of Shandong Province Natural Science Foundation (ZR2018ZA0602), Taishan Scholars Project Special Funding (TS20190935), and Development plan of Excellent Youth Innovation Team in Colleges and universities of Shandong Province (2019KJH006).

\section{References}

[1] S. J. Chen, X. Qu, D. W. Yin, X. Q. Liu, H. F. Ma, and H. Y. Wang, "Investigation lateral deformation and failure characteristics of strip coal pillar in deep mining," Geomechanics and Engineering, vol. 14, no. 5, pp. 421-428, 2018.

[2] I. Palmer, "Coalbed methane wells are cheap, but permeability can be expensive," Energy Tribune, vol. 3, pp. 10-13, 2008.

[3] T. B. Zhao, W. Y. Guo, Y. L. Tan, Y. C. Yin, L. S. Cai, and J. F. Pan, "Case studies of rock bursts under complicated geological conditions during multi-seam mining at a depth of $800 \mathrm{~m}$," Rock Mechanics and Rock Engineering., vol. 51, no. 5, pp. 1539-1564, 2018.

[4] T. Fan, G. Zhou, and J. Y. Wang, "Preparation and characterization of a wetting-agglomeration-based hybrid coal dust suppressant," Process Safety \& Environmental Protection, vol. 113, pp. 282-291, 2018.

[5] Q. C. Fang, Z. Q. Li, and K. P. Zhou, "Study of rational water injection parameters of hydraulic pressing preventing outburst measure based on numerical simulation," Procedia Engineering, vol. 26, pp. 1097-1103, 2011.

[6] G. Zhou, Q. Zhang, R. N. Bai, T. Fan, and G. Wang, "The diffusion behavior law of respirable dust at fully mechanized caving face in coal mine: CFD numerical simulation and engineering application," Process Safety and Environmental Protection., vol. 106, pp. 117-128, 2017.
[7] C. J. Fan, S. Li, M. K. Luo, Z. H. Yang, H. H. Zhang, and S. Wang, "Deep CBM extraction numerical simulation based on hydraulic-mechanical-thermal coupled model," Journal of China Coal Society., vol. 12, pp. 3076-3085, 2016.

[8] Q. Z. Li, B. Q. Lin, W. Yang, C. Zhai, and Z. Y. Hao, "Gas control technology and engineering practice for three-soft coal seam with low permeability in XuanGang region, China," Procedia Engineering, vol. 26, pp. 560-569, 2011.

[9] K. W. Wang, "Study on technology of fracturing and permeability improved of coal seam with high pressure air blasting," Coal Science and Technology., vol. 46, no. 2, pp. 193-197, 2018.

[10] A. Keshavarz, A. Badalyan, T. Carageorgos, P. Bedrikovetsky, and R. Johnson, "Stimulation of coal seam permeability by micro-sized graded proppant placement using selective fluid properties," Fuel, vol. 144, pp. 228-236, 2015.

[11] C. Zhang, B. Q. Lin, Y. Zhou, C. Zhuo, C. Zhou, and X. Sun, "Deep-hole directional static cracking technique for pressure relief and permeability improvement in mining-coal bed," Journal of Mining \& Safety Engineering, vol. 30, no. 4, pp. 600-604, 2013.

[12] X. L. Zhang, B. Q. Lin, C. J. Zhu et al., "Petrophysical variation of coal treated by cyclic high-voltage electrical pulse for coalbed methane recovery," Journal of Petroleum Science and Engineering., vol. 178, pp. 795-804, 2019.

[13] J. P. Zou, Y. Y. Jiao, T. D. Rathnaweera, and H. Wang, "Experimental study on the influence of temperature cycle on lowrank coal permeability," Science China Technological Sciences., vol. 63, no. 6, pp. 1055-1065, 2020.

[14] A. Shahtalebi, C. Khan, A. Dmyterko, P. Shukla, and V. Rudolph, "Investigation of thermal stimulation of coal seam gas fields for accelerated gas recovery," Fuel, vol. 180, pp. 301313, 2016.

[15] D. Yu, Y. Jia, X. Yu et al., "Research on fracture propagation by cryogenic volume fracturing based on DEM," in In Proceedings of the International Field Exploration and Development Conference 2017, pp. 1673-1684, Springer, Singapore, 2019.

[16] A. S. Ranathunga, M. S. A. Perera, P. G. Ranjith, and C. H. Wei, "An experimental investigation of applicability of $\mathrm{CO} 2$ enhanced coal bed methane recovery to low rank coal," Fuel, vol. 189, pp. 391-399, 2017.

[17] B. F. Van, P. Krzystolik, W. N. Van et al., "Production of gas from coal seams in the Upper Silesian Coal Basin in Poland in the post-injection period of an ECBM pilot site," International Journal of Coal Geology, vol. 77, no. 1-2, pp. 175-187, 2009.

[18] S. J. Zarrouk and T. A. Moore, "Preliminary reservoir model of enhanced coalbed methane (ECBM) in a subbituminous coal seam, Huntly Coalfield, New Zealand," International Journal of Coal Geology, vol. 77, no. 1-2, pp. 153-161, 2009.

[19] M. Economides, R. Oligney, and P. Valkó, Unified Fracture Design: Bridging the Gap between Theory and Practice, Orsa Press, New York, NY, 2002.

[20] G. H. Ni, Z. Li, and H. C. Xie, "The mechanism and relief method of the coal seam water blocking effect (WBE) based on the surfactants," Powder Technology., vol. 323, pp. 60-68, 2018.

[21] J. Seidle, Fundamentals of Coalbed Methane Reservoir Engineering, Penn Well Books, Tulsa, TU, 2011.

[22] B. Q. Lin, F. Z. Yan, C. J. Zhu et al., "Cross-borehole hydraulic slotting technique for preventing and controlling coal and gas outbursts during coal roadway excavation," Journal of Natural Gas Science \& Engineering., vol. 26, pp. 518-525, 2015. 
[23] F. Z. Yan, B. Q. Lin, C. J. Zhu et al., "A novel ECBM extraction technology based on the integration of hydraulic slotting and hydraulic fracturing," Journal of Natural Gas Science and Engineering., vol. 22, pp. 571-579, 2015.

[24] Y. P. Cheng, J. H. Fu, and Q. X. Yu, "Development of gas extraction technology in coal mines of China," Journal of Mining \& Safety Engineering., vol. 2, pp. 127-139, 2009.

[25] Z. Liu, H. Yang, W. M. Cheng, L. Xin, and G. H. Ni, "Stress distribution characteristic analysis and control of coal and gas outburst disaster in a pressure-relief boundary area in protective layer mining," Arabian Journal of Geosciences, vol. 10, no. 16, p. 358, 2017.

[26] H. W. Zhou, H. P. Xie, and J. P. Zuo, "Meta-property right, derived property right and right of modification of biogenetic resources," Biodiversity Science, vol. 13, no. 4, pp. 363-399, 2005.

[27] Y. Li, S. Cao, N. Fantuzzi, and Y. Liu, "Elasto-plastic analysis of a circular borehole in elastic-strain softening coal seams," International Journal of Rock Mechanics and Mining Sciences., vol. 80, pp. 316-324, 2015.

[28] Z. Liu, Z. H. Li, and Y. L. Yang, "Study of outburst prevention technology by comprehensive hydraulic drilling downward through coal-seam," Journal of Mining \& Safety Engineering, vol. 29, no. 4, pp. 564-569, 2012.

[29] D. W. Yin, S. J. Chen, X. Q. Liu, and H. F. Ma, "Simulation study on strength and failure characteristics for granite with a set of cross-joints of different lengths," Advances in Civil Engineering., vol. 2018, article 2384579, pp. 1-10, 2018.

[30] G. Wang, M. M. Wu, R. Wang, H. Xu, and X. Song, "Height of the mining-induced fractured zone above a coal face," Engineering Geology, vol. 216, pp. 140-152, 2017.

[31] X. G. Kong, E. Y. Wang, X. F. Liu et al., "Coupled analysis about multi-factors to the effective influence radius of hydraulic flushing: application of response surface methodology," Journal of Natural Gas Science and Engineering., vol. 32, pp. 538-548, 2016.

[32] S. Durucan and J. S. Edwards, "The effects of stress and fracturing on permeability of coal," Mining Science and Technology, vol. 3, no. 3, pp. 205-216, 1986. 